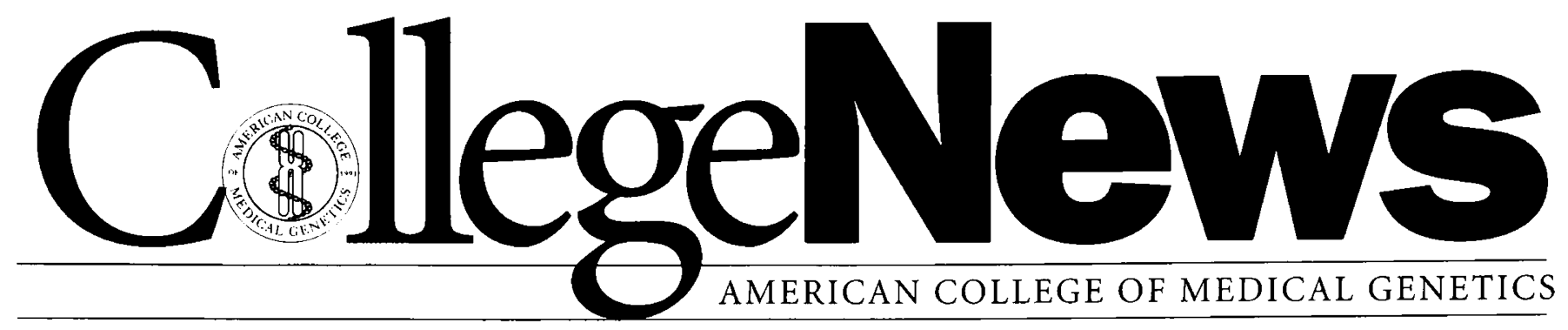

\section{Cover Art Story: The Family Tree}

Designed and stitched by Josephine B. Rice. Photographed by Ted Rice.

It is befitting that this exquisite quilt adorns the cover of this issue of Genetics in Medicine for many reasons. It was stitched and designed by my paternal aunt, Josephine Bennett Rice, to grace my office in the University of Washington Medical Center. Aunt Jo and her husband Chuck were my primary supports as I struggled with my heavy course load as an undergraduate student at Kenyon College. My dream was to become a genetic counselor. Now, 15 plus years later, I find the table has turned as I have the opportunity to provide support for
Aunt Jo and her family. As she was stitching up the hem of my quilt, she learned that her grandson was to be born with trisomy 13. Brian Alan Forthofer was born on March 5, 1997. He died less than 24 hours later. This quilt is dedicated to his memory.

You will recognize many of the underlying themes in genetics in this artwork. Of course, the twisted double helix outlined in gold is the central motif, because this is the structure of our work. You will notice that my aunt's base pairing is a bit off-but such variations in DNA are the essence of our passion. Colorful chromosomes surround the DNA. Ten years ago, who would have thought that our standard gray karyotypes would be competing with the rainbow of chromosomes now available through spectral chromosome analysis. Pedigree symbols, the

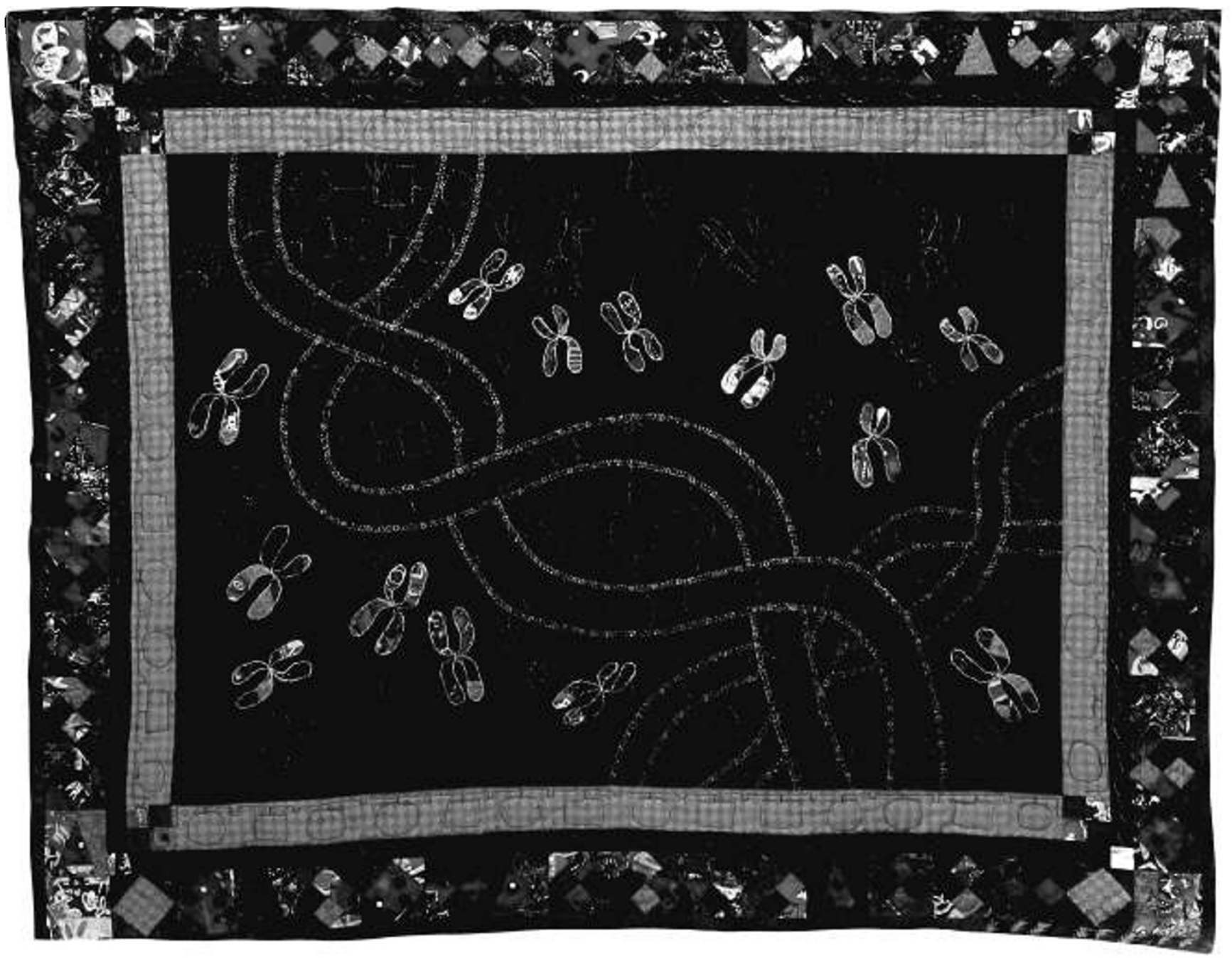


foundation of our genetics assessment, adorn the quilt's border. Keen genetic art connoisseurs will note the numerous sperm that compose the border. Without them, we would be unemployed.

The genetic themes are obvious in Aunt Jo's quilt; the human tones are subtler. Notice that the chromosomes contain human faces. These cloth faces are in numerous colors with varying expressions, much like the potpourri of families we see every day for genetic counseling. Look closer and you will see a small white square in the right-hand corner stitched with the name Brian. What you cannot see are the tearstains. My aunt tells me that quilters have their own network of individuals involved with quilting and grief therapy. My cousin is working through her own pain by planning to stitch a quilt to give to the NICU where Brian lived his short life. Like quilters we use tried and true templates to recognize patterns of disease and of inheritance. Yet, even within the most common patterns, we realize each family encounter is unique. As we set new standards in genetic services and forge forward with genetic advances, we must remember the fabrics of peoples' lives that are the crux of these patterns.

Robin L. Bennett, MS, CGC Division of Medical Genetics, University of Washington Medical Center

\section{BPMC Drops hCG Patent Infringement Lawsuit Against Kaiser}

Claims of patent infringement against Kaiser Permanente have been dropped by the Biomedical Patent Management Company (BPMC). BPMC claimed that Kaiser infringed its rights in the hCG patent by performing multiple marker screening for the prenatal prediction of the risk of Down syndrome and other fetal abnormalities. The Consortium Opposed to [the hCG] Patent (COP) had contributed both financial and intellectual support to Kaiser Permanente. COP is supported by ACMG, the American Medical Association, the College of American Pathologists, the American College of Obstetricians and Gynecologists, the Association of American Medical Colleges, and a number of laboratories. Kaiser Permanente is a nonprofit health maintenance organization serving 8.5 million members in 17 states and the District of Columbia.

In seeking to dismiss the Kaiser Permanente case, BPMC has agreed not to sue Kaiser for performance of triple marker screening tests. The settlement agreement covers all triple marker screens done by Kaiser's laboratories and allows Kaiser to increase its testing volume by $10 \%$ per year over the life of the patent.

Kaiser sued BPMC in August 1997 for attempts to seek licensing agreements from Kaiser for prenatal screening tests utilizing the hCG analyte. The lawsuit sought to invalidate the patent and to determine that Kaiser's triple marker screening test did not infringe the patent. Kaiser's lawsuit was initiated in federal court in San Francisco. BPMC countersued, claiming patent infringement. After prolonged venue arguments, the Kaiser case was dismissed from the aforementioned court on jurisdictional grounds. BPMC subsequently filed its own suit in a federal court in San Diego.

Because the case had not reached the point at which its merits were presented to the court, it remains unclear as to the specific reasons that BPMC dropped its case. Michael Jacobs, from the firm of Morrison and Foerster, LLP, in San Francisco, represented Kaiser in the case. Jacobs speculates that BPMC “didn't want to have their patent tested in court." Although the decision is limited to the performance of this test by Kaiser, Jacobs believes that the outcome of the case has broader implications for other laboratories providing this test which have received letters from BPMC demanding licensing fees for the test. Jacobs said that "it should be clear to targets of the letters that there is value in relying on the courts to decide whether this patent is valid and infringed. The consortium has not finally defeated BPMC, but it has stopped it dead in its tracks."

Mitchell Sugarman, Kaiser's Director of Medical Technology Assessment, said, "We continue to believe that BPMC's patent is invalid and that this widely used test to detect serious birth defects should be affordable and available to all pregnant women in the country."

Michael S. Watson, PhD

Chair, Laboratory Practice Committee

\section{ACMGAnnouncements}

\section{Clinical Molecular Genetics Review Course May 14-16, 1999, DoubleTree Hotel, Charlotte, North Carolina}

The Southeast Regional Genetics Group (SERGG) is offering a review course for persons planning to take the American Board of Medical Genetics examination. The course will consist of a self-test and an intense review of clinical molecular genetics over a two day period. Course faculty are all active laboratory directors and recent ABMG diplomates with specialities in clinical molecular genetics. The course will be held May 14-16, 1999 at the DoubleTree Hotel, 895 West Trade Street, Charlotte, North Carolina 28202. Please contact the hotel for reservations (800) 222-TREE, http://www.doubletree.com/DoubleT/ Hotel61/70/70Main.htm. There is no course registration fee, although attendance may be limited to 25 registrants with priority given to those taking the molecular genetics specialty exam. For further information or to make a reservation, please contact O. Thomas Mueller, PhD (727) 8928985, E-mail: muellert@allkids.org or Suzanne Hart, PhD (336) 716-4321, E-mail: pshart@wfubmc.edu. 


\section{PositionsAvailable}

\section{Immediate Position Available: Genetic Counselor}

The Department of Pediatrics, University of Arkansas for Medical Sciences (UAMS) at Arkansas Children's Hospital $(\mathrm{ACH})$, has an immediate opening for a board certified/board eligible genetic counselor. Prior experience is not necessary. Our team conducts outpatient clinics (pediatric and adult) and inpatient consults (pediatric) at UAMS/ACH. Currently, one regional genetics clinic is held every other month in beautiful Northwest Arkansas. Participation in professional education is possible. Opportunities for development of innovative ideas in patient care and for personal advancement. Other division staff members include a clinical geneticist, a biochemical geneticist, and a specialty nurse/genetic counselor. Other genetic counselors at UAMS interacting with our Clinical Genetics Division include three prenatal genetic counselors and a cancer genetic counselor.

Amenities include competitive salary with excellent fringe benefits, comprehensive genetics program, opportunity for personal development, great weather.

Send CV, letter of interest, and three references to: Mary Curtis, MD, Department of Pediatrics, University of Arkansas for Medical Sciences, 4301 West Markham, Slot 512-22, Little Rock, AR 72205, Phone: (501) 3202966, Fax: (501) 320-1564.

\section{Position Available: Associate Director, Cytogenetics Laboratory}

DIANON Systems, Inc., has an immediate opening for an Associate Director of our clinical cytogenetics laboratory. DIANON Systems, Inc., is a nationwide provider of anatomic pathology testing, and our cytogenetics laboratory is an integral part of our test offering. This lab currently processes approximately 650 amniotic fluid, blood, bone marrow, and solid tissue samples per month, and volume continues to increase.

In addition to assuming day-to-day management and budgetary responsibilities for the cytogenetics laboratory, the Associate Director will share clinical signout responsibilities with the Laboratory Director. The successful candidate must therefore have experience in all aspects of laboratory management, as well as excellent written and verbal communication skills. Experience with FISH and personal computing skills are also necessary.

Candidates must be board certified (or board eligible) in clinical cytogenetics by the American Board of Medical Genetics, with at least 3 years of clinical cytogenetics laboratory management experience. New York State Department of Health Certificate of Qualification in Cytogenetics preferred.

DIANON'S competitive compensation is accompanied by an excellent benefits package, including medical/ dental insurance and 401(k). Relocation assistance is available. Please send your resume to: Manager, Human Resources, DIANON Systems, Inc., 200 Watson BIvd., Stratford, CT 06497; Fax: (203) 380-4590. DIANON Systems, Inc., is an equal opportunity employer.

\section{Position Available: Postdoctoral Research}

The Division of Medical Genetics, Emory University School of Medicine, is seeking a motivated, productive investigator with interest and skills in analyzing the regulation of human gene expression. Knowledge of mammalian cell culture and protein biochemistry is a plus. Send curriculum vitae, a brief statement of career goals, and names of three references to: Louis J. Elsas II, MD, Department of Pediatrics, Division of Medical Genetics, Emory University School of Medicine, 2040 Ridgewood Drive, Atlanta, GA 30322. Fax: (404) 727 5783. Emory University is an EEO/AA employer.

\section{Position Available: ABMG Certified Clinical Geneticist}

The Section of Medical Genetics and Molecular Medicine at Children's Mercy Hospital in Kansas City, Missouri, is recruiting a clinical geneticist to join the practice with two board certified clinical geneticists. In addition to clinical activities, there will be opportunities for independent and collaborative research and education. The Section has an active clinical genetics service, including general, prenatal, and metabolic genetics. Presently, we have one MD/PhD, one MD, four PhD geneticists, three genetic counselors, one social worker, and one parent support specialist.

Children's Mercy Hospital is a tertiary care pediatric facility which supplies immediate genetic services for families from western Missouri and eastern Kansas. Children's Mercy Hospital is affiliated with the University of Missouri-Kansas City School of Medicine. The outreach and specialty genetics clinics are supported by comprehensive DNA Diagnostic, Cytogenetics, and Biochemical Genetics Laboratories. Faculty appointments and compensation are commensurate with qualifications and experience. There is an excellent benefit package. Children's Mercy Hospital is an equal opportunity employer.

Applicants should submit a letter of interest, CV and bibliography, and three references to: Merlin G. Butler, MD, PhD, Children's Mercy Hospital, Section of Medical Genetics, 2401 Gillham Road, Kansas City, MO 64108.

\section{Position Available: Genetic Technologist, Research/Clinical}

Baystate Medical Center, an 800-bed teaching hospital (Western Campus Tufts University School of Medicine) has an immediate opening available for a research and clinical technologist with a minimum of 1 year experience. The laboratory offers a full range of diagnostic genetic 
services, including prenatal, pediatric, cancer, and molecular. A Bachelor's degree is desired and experience in molecular techniques and FISH is preferred. Working conditions, benefits, and salaries are highly competitive and among the best in New England. Salary depends on experience and skills. The hospital is located in Springfield, MA, and is less than two hours from Boston and three hours from Manhattan. The community offers low cost of living, abundant educational and cultural and recreational resources. Applicants should respond by fax or e-mail in a letter stating their goals, resume, and the names of three references addressed to: Rizwan C. Naeem, MD, FACMG, Director, Laboratory Genetics, Baystate Medical Center, 759 Chestnut Street, Springfield, MA 01199; Phone: (413) 794-5130; Fax: (413) 794-5481; E-mail: rizwan.naeem@bhs.org

\section{Position Available: Cytogenetics Laboratory Director}

Genzyme Genetics seeks applicants for its Santa Fe, New Mexico facility. Candidates must be American Board of Medical Genetics certified in clinical cytogenetics. Significant experience in managing a cytogenetics laboratory is required. Interested applicants should submit a letter of interest, CV, salary requirements, and list of references to Diane Marbourg, Human Resources Manager, Job No. AJHG 199, Genzyme Genetics, 2000 Vivigen Way, Santa Fe, NM 87505; or fax to: (505) 4382277. Genzyme Genetics is an Equal Opportunity Employer that is proud of the diversity of its workforce.

\section{Position Available: Assistant Director, Cytogenetics Laboratory}

The Department of Laboratory Medicine at Children's Hospital seeks applicants for the position of Assistant Director of the Cytogenetics Laboratory. The laboratory processes approximately 2700 prenatal, peripheral blood, and non-neoplastic tissue specimens annually. Applicants should be doctoral-level cytogeneticist certified or eligible for certification by the American Board of Medical Genetics. Major responsibilities include participation in directing and supervising an expanding clinical cytogenetic and molecular cytogenetic laboratory, cooperative work in a research program, and participation in teaching activities. The successful candidate will have a joint faculty appointment in the Ohio State University College of Medicine Department of Pathology with rank based on academic experience. Applicants should submit a letter of interest, CV, and names and addresses of three references to Dr. Gail D. Wenger, Director Cytogenetics Laboratory, Children's Hospital, 700 Children's Drive, Columbus, Ohio 43205. Children's Hospital is an equal opportunity, affirmative action employer.

\section{Position Available: Cytogeneticist}

The Kaiser Permanente Medical Group in Northern California currently seeks a cytogenetics professional to join our multidisciplinary management team as an assistant or co-director. Located in San Jose, our full-service diagnostic cytogenetics laboratory processes more than 7,000 prenatal, postnatal, and cancer specimens annually and has a large molecular cytogenetics component. Together, our cytogenetics and molecular labs occupy a 10,000 square foot facility with state-of-the-art equipment. Along with your $\mathrm{PhD}$ in a field related to genetics, we require completion of a 2-year ABMG approved training program in clinical cytogenetics and ABMG board certification/eligibility in clinial cytogenetics. Experience with molecular cytogenetics techniques is preferred. For consideration, please send a CV and letter of interest to Debra Lee, Staff Specialist, Genetics Department, 5755 Cottle Rd., Building One, San Jose, CA 95123, phone (408) 972-3342, fax (408) 972-3298, or e-mail Debra.Lee@Ncal.Kaiperm.org. We are an EEO/AA employer.

\section{Position Available: Director of Joint Program in Prenatal Diagnosis}

Women \& Infants Hospital seeks an ob/gyn-trained clinical geneticist as Director of its Joint Program in Prenatal Diagnosis. The Hospital provides tertiary services for 20,000 births annually. The Director will provide administrative, scientific, and clinical leadership for the Program, which provides services in the Departments of OB/Gyn and Pathology, including counseling, imaging, invasive techniques, and biochemical, cytogenetic and molecular testing. Candidates must be certified in Obstetrics and Gynecology (American Board of Obstetrics and Gynecology) and in Clinical Genetics (American Board of Medical Genetics), have management experience in a prenatal diagnosis environment, have an active investigative focus, and qualify for appointment at the rank of Associate or Full Professor at Brown University. Women \& Infants Hospital is an Equal Employment/Affirmative Action employer and encourages applications from women, minorities, and protected persons. Inquiries to Marshall Carpenter, MD, Women \& Infants Hospital, 101 Dudley Street, Providence, RI 02905-2401 (fax: (401) 453-7722; E-mail: mcarpent@wihn.org).

\section{Research Projects: Anophthalmia/Microphthalmia Registry and DNA}

The Division of Genetics at Albert Einstein Medical Center in Philadelphia, PA, has undertaken two projects to study anophthalmia/microphthalmia (A/M). We have designed a comprehensive registry questionnaire which ascertains family history, pregnancy, and environmental exposure histories and medical history of children who have $A / M$. This questionnaire is sent to interested families to complete. Our goal is to identify all of the genetic syndromes associated with $\mathrm{A} / \mathrm{M}$, to provide accurate recurrence risks for genetic counseling, to explore the possible genes that cause $\mathrm{A} / \mathrm{M}$, and to identify whether there may be any environmental agents resulting in 
A/M. Additionally, we are currently participating in another project which is a collaborative effort with researchers who are studying the role of eye development genes in $\mathrm{A} / \mathrm{M}$. For more information, please contact Joyce at (215) 456-8722.

\section{Accepting Applications: Graduate Diploma in Genetic Counseling}

Administered by the Faculty of Medicine and Health Sciences at the University of Newcastle, New South Wales, Australia, and taught by clinical staff of Hunter Genetics, a department of the Hunter Area Health Service. The Graduate Diploma in Genetic Counseling is open to people with a basic degree in science, psychology, nursing, education, or equivalent professional experience, and can be taken as a 1-year full-time course or longer part time. Overseas students are welcome to apply. It is a full fee-paying course costing $\$ 6400$ for Australian students. Higher fees apply to overseas students.

There is a heavy emphasis on clinical and practical training and problem-based self-directed learning in all parts of the course. Attendance at clinics, home visits before and after clinic assessments, prenatal diagnosis clinics at the John Hunter Hospital, cancer genetics clinics, and neurogenetic clinics are a compulsory part of the practicum. Video role play interviews are also used. The practicum also consists of two 3-week periods in which students attend their choice of genetics units elsewhere in New South Wales or interstate, cytogenetics, screening, or molecular laboratories, prenatal diagnosis units, fertility units, genetics education unit, or other centers of relevance to genetic counseling.

Students who choose to complete the Master's degree first complete the graduate diploma course, then undertake a year of approved research and present their results in a mini-thesis. The Master's degree entails a further 80 credit points. Scholarships are available for selected students.

Applications closed in November 1998, but late applications will be considered if the course is not full.

For further information, contact: Matt Edwards, Staff Specialist, Hunter Genetics, P.O. Box 84, Waratah, NSW 2298, Australia. Senior-lecturer, University of Newcastle; Phone: 61-2-49-853100; Fax 61-2-49853105; Mobile 0407-239-663. 